“Historical Studies on Mortality," special issue, Canadian Studies in Population 39, no. 3-4 (2012): 129-130.

\title{
The Great Migration: Rural-Urban Migration in China and Indonesia
}

\author{
Edited by Xin Meng and Chris Manning, with Li Shi and Tadjuddin Noer Effendi \\ Cheltenham (UK): Edward Elgar, 2010 \\ ISBN 978-1-84844-644 \\ Hardcover, \$125.00, 262 pp.
}

\author{
Reviewed by Zongli Tang \\ Auburn University at Montgomery \\ ztang@aum.edu
}

Rapid economic growth and industrialization in China have stimulated more and more peasants to move to urban regions since the 1990s. World Bank estimated the figure to reach 130 million in 2005. And according to the Chinese government, more than 200 million peasants now live and work in cities. The largest scale of rural-urban migration in human history has quickly changed China, and it has also caught attentions of both Western and Chinese anthropologists, sociologists, and economists. Meanwhile, Indonesia, another Asian-country with a large population, has experienced a fast urbanization process similar to China. In 2005, 43 per cent of Indonesians inhabited cities. However, in 1980, the rate was only 22 per cent. The speed of urbanization in the two countries is faster than most developed countries including the UK and Japan during their process of industrialization. For instance, it took China for 10 years (between 1995 and 2005) to increase to 130 million from 40 million of peasants who moved to cities, whereas during the 60 years of 1841-1901, the height of Industrial Revolution in the UK, only 3 million moved from rural to urban areas. To understand the migration processes in China and Indonesia and provide the most recent information for governments in their policymaking, researchers at the Australian National University, the Queensland University of Technology, the Beijing Normal University and Gadjah Mada University, initiated the project of Rural-Urban Migration in China and Indonesia (RUMiCI). This project plans to conduct five waves of surveys in the two countries over a five year span. This book reports findings of the first wave, which was conducted in early 2008.

This book consists of two parts in addition to Chapter 1, which briefly demonstrates the whole research project and gives an overview of findings in the two countries. The six chapters in the first part focus on rural-urban migration issues in China. In Chapter 2, Leng Lee and Xin Meng, using data from the Urban Migrant Survey, examine what sort of people migrated from rural areas, and why some peasants chose not to migrate. According to their analyses, most of these rural migrants were young people aged 18-35, better educated than those who did not move. Monetary impulse was the main push factor. Age and need to look after children and elderly at home were the main factors in discouraging migration among certain groups. In Chapter 3, Paul Frijters, Leng Lee and Xin Meng make comparisons of remuneration packages between rural migrants and urban workers who hold bukou (i.e., official permission to live in the city). In addition to lower starting salaries as compared with urban workers, rural migrants were paid lower weekly wages and worked longer. Rural migrants also received less percentage of non-wage remunerations including unemployment insurance, pension insurance, health insurance, work injury insurance, and housing funds than urban bukou holders. This was another factor in discouraging peasant moving to cities. In Chapter 4, Deng Quheng and Li Shi discuss the inequality of wages and careers between migrants and native urban workers as brought by the bukou system (i.e., household registration system). Under this system, only those who held an urban bukou were eligible to obtain certain types of jobs. Therefore, urban bukou holders concentrated largely on professional and managerial jobs, but most migrants, by contrast, were blue-collar workers.

The children of migrants either moved to cities with their parents or stayed behind in villages, cared for by their grandparents or relatives. In Chapter 5, Sherry Tao Kong and Xin Meng look into the educational and health outcomes of these children. Based on the survey data, they concluded that as compared with their urban fellows, the children of migrants were less likely to have good school performance. Besides, the long-term health status of these children was not as good as that of urban children, even worse than that of rural children whose parents did not move to cities. 
Chapter 6, written by Chulian Luo and Ximing Yue, investigates the role of migration in alleviating rural poverty. The results show that migrants brought back money from cities and improved significantly the level of standard of living of their family members left behind in rural villages. In Chapter 7, Sherry Tao Kong illustrates survey design, research methods, and data collection procedure carried out in China.

The second part of the book, which consists of four chapters, involves survey findings from Indonesia. In Chapter 8, Tadjuddin Noer Effendi, Mujiyani Fina Itriyati, Danang Arif Darmawan and Derajad S. Widhyharto analyze the demographic, social and employment characteristics of migrant and non-migrant households. In Chapter 9, Budy P. Resosudarmo, ASEP Suryahadi, Raden M. Purnagunawan, Athia Yumna and Asri Yusrina discuss their findings that the income of migrant families was much higher than non-migrant families in rural areas. As for health status, they do not find evident differences between the two groups. In Chapter 10, Armida Alisjahbana and Chris Manning examine data with regard to job allocation and earnings among recent and long-term migrants versus non-migrants. They discover that migrants who entered the labor market recently were likely to be at a disadvantage to long-term migrants and nonmigrant (or urban residents). The earnings of these recent migrants were lower either because they were younger and less experienced or because they were engaged in unskilled occupations. Their situation was similar to rural migrants in China. In Chapter 11, Budy P. Resosudarmo, Chilako Yamauchi and Tadjuddin Noer Effendi interpret survey design and implementation in Indonesia. The Rural-Urban Migration Project in Indonesia was conducted somewhat differently from that in China. The Indonesian survey involved urban areas only, whereas the Chinese study was implemented in both urban and rural areas. As there is no household registration system (bukou) in Indonesia, rural migrants, who moved to cities and resided there for more than one year, would be considered urban residents. Yet, these rural migrants would not be treated as urban residents in China if they did not obtain urban bukou.

The data collected in this project cover a wide range of issues, including occupations rural migrants engaged in, their earning, working hours, welfare, education, health status, and comparisons between them and others, namely non-migrants and urban residents. These issues are not novel, and we have seen them in Chinese and English literature. The uniqueness is the sample size and the regions investigated in this project. The Chinese surveys were conducted in 10 provinces that are major migrant-sending and migrant-receiving regions, including Shanghai, Jiangau, Zhejiang, Guangdong, Sichuan, Chongqing, Henan, Anhui, Hubei and Hebei, consisting of three surveys: the Urban Migrant Survey (5000 households in 15 cities), the Urban Household Survey (5000 in 19 cities), and the Rural Household Survey (8000 in 10 provinces). The Indonesian surveys were conducted in four cities: Tangerang in Java, Medan in Sumatra, Samarinda in Kalimantan, and Makassar in Sulawesi, sampling 900 non-migrant households, 900 long-term migrant households, and 600 recent migrant households. This type of survey with such a large size and broad coverage has never been done before either in China or Indonesia.

Of the three surveys in China, the Urban Household Survey and the Rural Household Survey were run by China's National Bureau of Statistics. The samples were randomly selected from the household income and expenditure surveys that are carried out annually by the Bureau. In other words, the two surveys came from the existing data. Hence, the Urban Migrant Survey becomes the only one completed by the RUMiCI project, and it was operated by the project team in collaboration with Datasea Marketing Research, a Shanghai-based professional survey company. Given the migrant size (of about 200 million in China), it is not easy to administer a nationwide survey. There are so many issues complicating the investigation. For instance, a complete list of all migrants in the cities under investigation is necessary to draw a random sample. However, it is almost impossible to obtain such a list especially in China, where, as the authors admitted, an extensive under-coverage of rural migrants is present with official registration. To overcome this problem, the team members first randomly selected enumeration areas in each city, and detected out all the business enterprises in each enumeration area. Then, they visited the business units one by one as located in that area, acquiring information of all rural migrants working there. From the information obtained, they established a list of 550,000 migrant workers, from which 5,000 were randomly selected for face-to-face interview. Even with these efforts, the problem of under-coverage, especially with small business, countryside-based-business, individual entrepreneurs, and individual workers, was not solved. I have some concerns with the under-coverage problem of female migrants as many of them were engaged in small business like street vendors and living-in baby-sitter that were never registered as licensed business.

The Chinese government introduced bukou system in the 1950s in an attempt to restrict movement from rural areas to cities and control urban population size. Indonesian government does not have such a desire to keep rural population in the countryside, and has not imposed any restrictions on population mobility. This could lead to a series of distinctions in migration patterns between China and Indonesia. However, this study simply displays survey results in the two countries in the two separate parts. We do not find a penetrating comparative analysis as expected. While this book was written by a number of researchers, a coordinating work in an overall manner would have needed considerably, for overlapping discussions and analyses appeared throughout chapters. 